\title{
Extracorporeal treatment for carbamazepine poisoning: Systematic review and recommendations from the EXTRIP workgroup
}

\author{
MARC GHANNOUM,,${ }^{1}$ CHRISTOPHER YATES, ${ }^{2}$ TAIS F. GALVAO,${ }^{3}$ KEVIN M. SOWINSKI, ${ }^{4}$ THI HAI VÂN VO, ${ }^{1}$ \\ ANDREW COOGAN, ${ }^{5}$ SOPHIE GOSSELIN, ${ }^{6}$ VALERY LAVERGNE,${ }^{7}$ THOMAS D. NOLIN, ${ }^{8}$ and ROBERT S. HOFFMAN ${ }^{9}$ \\ ON BEHALF OF THE EXTRIP WORKGROUP* \\ ${ }^{1}$ Division of Nephrology, Verdun Hospital, University of Montreal, Montreal, QC, Canada \\ ${ }^{2}$ Emergency Department and Clinical Toxicology Unit, Hospital Universitari Son Espases, Palma de Mallorca, Spain \\ ${ }^{3}$ Getulio Vargas University Hospital, Federal University of Amazonas, Manaus, AM, Brazil \\ ${ }^{4}$ Purdue University, College of Pharmacy, Department of Pharmacy Practice, Indianapolis and West Lafayette, IN \\ ${ }^{5}$ Department of Pharmacy and Therapeutics, Chinle Comprehensive Health Care Facility, Indian Health Services, Chinle, AZ, USA \\ ${ }^{6}$ Emergency Medicine and Medical Toxicology Service, McGill University Health Centre, Montréal, QC, Canada \\ ${ }^{7}$ Department of Biology, Hôpital Sacré-Cour de Montréal, University of Montreal, QC, Canada \\ ${ }^{8}$ Department of Pharmacy and Therapeutics, and Department of Medicine Renal Electrolyte Division, University of Pittsburgh Schools \\ of Pharmacy and Medicine, Pittsburgh, PA, USA \\ ${ }^{9}$ Departments of Medicine and Emergency Medicine New York University School of Medicine, New York, NY, USA
}

Context. The Extracorporeal Treatments in Poisoning (EXTRIP) workgroup was created to provide evidence and consensus-based recommendations on the use of extracorporeal treatments (ECTRs) in poisoning. Objectives. To perform a systematic review and provide clinical recommendations for ECTR in carbamazepine poisoning. Methods. After a systematic literature search, the subgroup extracted the data and summarized the findings following a pre-determined format. The entire workgroup voted via a two-round modified Delphi method to reach a consensus on voting statements, using a RAND/UCLA Appropriateness Method to quantify disagreement. Anonymous votes were compiled, returned, and discussed in person. A second vote determined the final recommendations. Results. Seventy-four articles met inclusion criteria. Articles included case reports, case series, descriptive cohorts, pharmacokinetic studies, and in-vitro studies; two poor-quality observational studies were identified, yielding a very low quality of evidence for all recommendations. Data on 173 patients, including 6 fatalities, were reviewed. The workgroup concluded that carbamazepine is moderately dialyzable and made the following recommendations: ECTR is suggested in severe carbamazepine poisoning (2D). ECTR is recommended if multiple seizures occur and are refractory to treatment (1D), or if life-threatening dysrhythmias occur (1D). ECTR is suggested if prolonged coma or respiratory depression requiring mechanical ventilation are present (2D) or if significant toxicity persists, particularly when carbamazepine concentrations rise or remain elevated, despite using multipledose activated charcoal (MDAC) and supportive measures (2D). ECTR should be continued until clinical improvement is apparent (1D) or the serum carbamazepine concentration is below $10 \mathrm{mg} / \mathrm{L}(42 \mu \mathrm{mol} / \mathrm{L})(2 \mathrm{D})$. Intermittent hemodialysis is the preferred ECTR (1D), but both intermittent hemoperfusion (1D) or continuous renal replacement therapies (3D) are alternatives if hemodialysis is not available. MDAC therapy should be continued during ECTR (1D). Conclusion. Despite the low quality of the available clinical evidence and the high protein binding capacity of carbamazepine, the workgroup suggested extracorporeal removal in cases of severe carbamazepine poisoning.

Keywords Hemodialysis; Hemoperfusion; Overdose; Anticonvulsant

\footnotetext{
Received 12 August 2014; accepted 1 October 2014.

*The EXTRIP workgroup also includes Kurt Anseeuw, Ashish Bhalla, Emmanuel A. Burdmann, Diane P. Calello, Paul I. Dargan, Brian S. Decker, David S. Goldfarb, Lotte C. Hoegberg, David N. Juurlink, Jan T. Kielstein, Martin Laliberté, Yi Li, Kathleen D. Liu, Robert MacLaren, Robert Mactier, Bruno Mégarbane, James B. Mowry, Véronique Phan, Darren M. Roberts, Timothy J. Wiegand, James F. Winchester.

This is an open-access article distributed under the terms of the CC-BYNC-ND 3.0 License which permits users to download and share the article for non-commercial purposes, so long as the article is reproduced in the whole without changes, and provided the original source is credited. Address correspondence to Dr. Marc Ghannoum, MD, FRCPC, Verdun Hospital, 4000 Lasalle Boulevard, Verdun, QC H4G2A3 Canada. E-mail: marcghannoum@gmail.com
}

\section{Introduction}

The Extracorporeal Treatments in Poisoning (EXTRIP) workgroup comprises international experts representing diverse specialties and professional societies (Table 1) brought together to provide recommendations, based on evidence and consensus, for the use of extracorporeal treatments (ECTRs) in poisoning (www.extrip-workgroup.org). Rationale, background, objectives, complete methodology, and its first recommendations have been published. ${ }^{1-6}$ The following text reviews the recommendations for carbamazepine. 
Table 1. Represented societies.

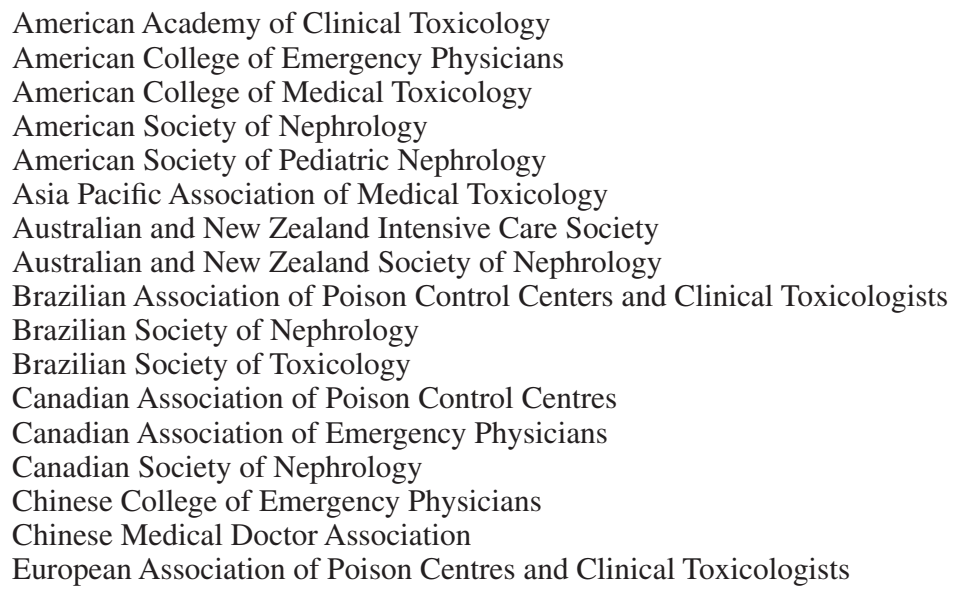

American Academy of Clinical Toxicology

American College of Emergency Physicians

American College of Medical Toxicology

American Society of Nephrology

American Society of Pediatric Nephrology

Asia Pacific Association of Medical Toxicology

Australian and New Zealand Intensive Care Society

Australian and New Zealand Society of Nephrology

Brazilian Association of Poison Control Centers and Clinical Toxicologists

Brazilian Society of Nephrology

Brazilian Society of Toxicology

Canadian Association of Poison Control Centres

Canadian Association of Emergency Physicians

Canadian Society of Nephrology

Chinese College of Emergency Physicians

Chinese Medical Doctor Association

European Association of Poison Centres and Clinical Toxicologists

European Renal Best Practice
European Society of Emergency Medicine
European Society of Intensive Care Medicine
French Language Society of Resuscitation
German Society of Nephrology
International Pediatric Nephrology Association
International Society of Nephrology
Latin American Society of Nephrology and Hypertension
National Kidney Foundation
Pediatric Continuous Renal Replacement Therapy
Pediatric Critical Care Medicine
Quebec Association of Emergency Physicians
Quebec Association of Specialists in Emergency Medicine
Quebec Society of Nephrology
Renal Association
Society of Critical Care Medicine
Spanish Clinical Toxicology Foundation

\section{Pharmacology}

Carbamazepine has a structure similar to that of tricyclic antidepressants and is used for the treatment of bipolar disorder, neuropathic pain, hyperactivity, and seizure disorder. It inhibits the release of glutamate and similar neurotransmitters via blockage of presynaptic voltage-gated sodium channels in the central nervous system (CNS). It also blocks $\mathrm{N}$-methyl D-aspartate and adenosine receptors. ${ }^{7}$

Carbamazepine has a molecular weight of $236 \mathrm{Da}$ and is highly bound to both albumin and alpha-1-acid glycoprotein (70-80\%), a percentage that does not appear to decrease significantly in overdose: in one series of 4 patients with supratherapeutic concentrations, protein binding remained at $74-82 \%,{ }^{8}$ while it decreased to $57 \%$ in another report. ${ }^{9}$ Carbamazepine has a slow rate of dissolution, which results in erratic and incomplete absorption. ${ }^{10,11}$ It is highly lipophilic and distributes rapidly and extensively (volume of distribution ranges from 0.8 to $1.4 \mathrm{~L} / \mathrm{Kg}$ ).

Carbamazepine is extensively metabolized in the liver by the cytochrome P450 system. Only 1-3\% of the drug is excreted unchanged in the urine. Its primary metabolite, carbamazepine-10,11-epoxide, is $50 \%$ protein-bound and shares an equal anticonvulsant and toxic effect. ${ }^{8}$ The nature of carbamazepine metabolism is complicated by the fact that it induces its own metabolism with chronic use; this auto-induction occurs relatively early in therapy, is dosedependent, and explains why carbamazepine-naïve patients usually exhibit more toxic symptoms at a given exposure than those who use it therapeutically.

Carbamazepine's half-life with initial dosing is reported to be $25-65 \mathrm{~h}$, which decreases to $12-17 \mathrm{~h}$ with repeated or continued dosing. In overdose, much longer apparent half-lives are reported, ${ }^{10,12}$ likely reflecting ongoing absorption, impaired elimination, or some combination of both processes.

\section{Overview of carbamazepine poisoning}

Toxicity from carbamazepine overdose was first described in $1967^{13}$ and continues to be responsible for a large proportion of life-threatening cases among anticonvulsant poisonings.
Data from the US Poison Control Centers documented 4149 toxic carbamazepine exposures in 2012, $14 \%$ of which had at least a moderate effect. ${ }^{115}$

Serum carbamazepine concentrations can be used to confirm exposure. The therapeutic concentration range is $4-12$ $\mathrm{mg} / \mathrm{L}(17-51 \mu \mathrm{mol} / \mathrm{L})$ (Table 2); significant toxicity usually occurs over $40 \mathrm{mg} / \mathrm{L}(169 \mu \mathrm{mol} / \mathrm{L}),{ }^{14}$ but also potentially at lower concentrations. ${ }^{15}$

Neurologic symptoms including movement disorders, altered mental status, and seizures primarily characterize carbamazepine toxicity. Respiratory depression is common in severe overdose and can be complicated by concomitant aspiration. Cardiovascular effects include sinus tachycardia, hypotension, myocardial depression, and cardiac conduction disturbances; in rare cases, QRS complex prolongation, bundle branch block, Brugada-type patterns, atrioventricular block, and premature ventricular contractions are reported. ${ }^{16-18}$ Death has been reported due to refractory cardiovascular toxicity. ${ }^{18-20}$

Medication clumping and slow dissolution may occur with standard and sustained-release formulations. ${ }^{21,22}$ At high concentrations, carbamazepine exhibits anticholinergic proprieties, which delays gastrointestinal motility further prolonging absorption, with peak absorption sometimes documented over 100 hours post-ingestion. ${ }^{12,17,23}$ Severely poisoned patients may suffer clinical deterioration after initial improvement or delayed onset toxicity that may result from rebounding or persistently high serum concentrations. Hyponatremia is a frequent adverse event during treatment, but is uncommon in cases of acute poisoning. Fatalities are extremely unusual, ${ }^{24}$ but in one large cohort of 427 patients,

Table 2. Carbamazepine physicochemical and toxicokinetic data.

\begin{tabular}{ll}
\hline Molecular weight & 236 Daltons \\
Volume of distribuition & $0.8-1.4 \mathrm{~L} / \mathrm{kg}$ \\
Protein binding & $75 \%$ \\
Oral bioavailability & $80-100 \%$ \\
Therapeutic range & $4-12 \mathrm{mg} / \mathrm{L}(17-51 \mu \mathrm{mol} / \mathrm{L})$ \\
Toxic exposure & $>20 \mathrm{mg} / \mathrm{kg}$ \\
Toxic blood concentrations & Adults: $>20 \mathrm{mg} / \mathrm{L}(85 \mu \mathrm{mol} / \mathrm{L})$ \\
& Children: $>12 \mathrm{mg} / \mathrm{L}(51 \mu \mathrm{mol} / \mathrm{L})$ \\
\hline
\end{tabular}


overall mortality following was $13 \%$; mean carbamazepine ingestion in lethal cases was 23.6 grams. ${ }^{15}$

Most cases of toxicity can be successfully managed with appropriate supportive care including airway protection with endotracheal intubation, treatment of seizures with benzodiazepines, and correction of hypotension with fluid challenges and vasopressors if needed. Hypertonic sodium bicarbonate can be used if evidence of sodium channel blockade is present on the electrocardiography. Gastrointestinal decontamination (e.g., single-dose activated charcoal) is indicated in those patients who present within 1-2 $\mathrm{h}$ after ingestion and have no contraindications. ${ }^{25}$

Multiple-dose activated charcoal (MDAC) increases elimination and improves clinical outcome in patients with carbamazepine overdose ${ }^{26}$ and is recommended for patients with life-threatening ingestions. ${ }^{27}$ However, the use of MDAC can be limited by decreased bowel motility, ${ }^{23,28-30}$ or concerns over airway protection. Although no antidotes are available to reverse the effects of carbamazepine, isolated case reports have described successful treatment of cardiovascular toxicity with lipid resuscitation therapy. ${ }^{31,32}$ Extracorporeal life support has also been used, ${ }^{17}$ but is technically complicated and not readily available in many hospital settings.

Recommendations from most consulted resources for ECTR in carbamazepine poisoning currently include the presence of life-threatening symptoms unresponsive to conventional treatment, ${ }^{33-37}$ or a contraindication to MDAC. ${ }^{36}$ There are concerns about the effectiveness of ECTR as some articles state that its effect on clearance is not superior to that of MDAC..$^{37,38}$ Therapeutic plasma exchange is mentioned, but evidence is limited and its use is not recommended. ${ }^{33,34,36}$

Oxcarbazepine has a molecular structure and clinical effects that are similar to carbamazepine; however, the scant data $^{39}$ cannot permit reliable extrapolation of the present recommendations to patients with oxcarbazepine poisoning.

\section{Methodology}

Pre-determined methodology incorporated guidelines from The Appraisal of Guidelines for Research and Evaluation
(AGREE) ${ }^{40}$ and Grades of Recommendation Assessment, Development and Evaluation (GRADE), ${ }^{41}$ and is described in detail elsewhere. ${ }^{2}$ The primary literature search was conducted on July 12th, 2012 in Medline, Embase, and Cochrane library (Systematic Reviews and CENTRAL).

The search strategy was as follows:

[(carbamazepin*) AND (dialysis OR hemodialysis OR haemodialysis OR hemoperfusion OR haemoperfusion OR plasmapheresis OR plasma exchange OR exchange transfusion OR hemofiltration OR haemofiltration OR hemodiafiltration OR haemodiafiltration OR extracorporeal therapy OR CRRT)]

A manual search in conference proceedings of the EAPCCT and NACCT annual meetings (until 2012), and Google Scholar was performed, as well as the bibliography of each article obtained during the literature search.

A subgroup of EXTRIP completed the literature search, reviewed each article, extracted data, and summarized findings. The level of evidence assigned to each clinical recommendation was determined by the subgroup and epidemiologist (Table 3). Dialyzability was determined based on criteria listed in Table 4. The potential benefit of the procedure was weighed against its cost, availability, alternative treatments, and its related complications. All of this information was submitted to the entire workgroup for consideration, along with structured voting statements based on a pre-determined format.

The strength of recommendations was evaluated by a two-round modified Delphi method for each proposed voting statement (Fig. 1) and RAND/UCLA Appropriateness Method was used to quantify disagreement between voters. ${ }^{42}$ Anonymous votes with comments were sent to the epidemiologist who then compiled and returned them to each participant. The workgroup met in person to exchange ideas and debate statements. A second vote was later submitted and these results were used in developing the core EXTRIP recommendations. The literature search was updated on October 1st 2014 following the same methodology as described above; the new articles and summarized data were submitted to every participant who then updated their votes.

Table 3. Strength of recommendation and level of evidence scaling on clinical outcomes.

\begin{tabular}{lc}
\hline Strength of recommendation (consensus-based) & Level of evidence (based on GRADE system) \\
\hline Level 1 = Strong recommendation = "We recommend..." & Grade A= High level of evidence \\
The course of action is considered appropriate by the majority of & The true effect lies close to our estimate of the effect \\
experts with no major dissension. The panel is confident that the & Grade $\mathrm{B}=$ Moderate level of evidence \\
desirable effects of adherence to the recommendation outweigh the & The true effect is likely to be close to our estimate of the effect, \\
undesirable effects & but there is a possibility that it is substantially different \\
Level 2 = Weak recommendation = "We suggest..." & Grade $\mathrm{C}=$ Low level of evidence \\
The course of action is considered appropriate by the majority of & The true effect may be substantially different from our estimate \\
experts, but some degree of dissension exists among the panel & of the effect \\
members. The desirable effects of adherence to the recommendation & Grade $\mathrm{D}=$ Very low level of evidence \\
probably outweigh the undesirable effects & Our estimate of the effect is just a guess, and it is very likely \\
Level $3=$ Neutral recommendation = "It would be reasonable..." & that the true effect is substantially different from our estimate \\
The course of action could be considered appropriate in the right & of the effect \\
context & \\
No recommendation & \\
No agreement was reached by the group of experts & \\
\hline
\end{tabular}


Table 4. Criteria of dialyzability.

\begin{tabular}{lcccc}
\hline Dialyzability & $\begin{array}{c}\text { Primary criteria } \\
\text { \% Removed }\end{array}$ & $\begin{array}{c}\text { Alternative criteria 1 } \\
\mathrm{CL}_{\mathrm{ECTR}} / \mathrm{CL}_{\mathrm{TOT}}(\%)^{\mathrm{C}}\end{array}$ & $\begin{array}{c}\text { Alternative criteria 2 } \\
\mathrm{T}_{1 / 2 \mathrm{ECTR}} / \mathrm{T}_{1 / 2}(\%)\end{array}$ & $\begin{array}{c}\text { Alternative criteria 3 } \\
\mathrm{Re}_{\mathrm{ECTR}} / \mathrm{Re}_{\mathrm{TOT}}(\%)^{\mathrm{C}}\end{array}$ \\
\hline D, Dialyzable & $>30$ & $>75$ & $<25$ & $>75$ \\
M, Moderately dialyzable & $>10-30$ & $>50-75$ & $>25-50$ & $>50-75$ \\
S, Slightly dialyzable & $\geq 3-10$ & $\geq 25-50$ & $>50-75$ & $\geq 25-50$ \\
N, Not dialyzable & $<3$ & $<25$ & $>75$ & $<25$ \\
\hline
\end{tabular}

A Applicable to all modalities of ECTR, including hemodialysis, hemoperfusion, and hemofiltration.

${ }^{\mathrm{B} C}$ Corresponds to \% removal of ingested dose or total body burden in a 6-hour ECTR period.

${ }^{\mathrm{C}}$ Measured during the same period of time.

$\mathrm{ECTR}=$ Extracorporeal treatment, $\mathrm{CL}_{\mathrm{ECTR}}=$ Extracorporeal clearance, $\mathrm{CL}_{\mathrm{TOT}}=$ Total clearance, $\mathrm{RE}_{\mathrm{ECTR}}=$ Extracorporeal removal, $\mathrm{RE}$ TOT $=\mathrm{Total}$ removal, $\mathrm{T}_{1 / 2 \text { ECTR }}=$ Half-life with ECTR, $\mathrm{T}_{1 / 2}=$ Half-life without ECTR.

*These criteria should only be applied if measured or calculated (not reported) endogenous half-life is $>4 \mathrm{~h}$ (otherwise, ECTR is not considered clinically relevant). Furthermore, the primary criteria are preferred for poisons having a large $\mathrm{Vd}(>5 \mathrm{~L} / \mathrm{Kg})$.

Reproduced with permission from Clinical Toxicology

\section{Results}

Results of the literature search are presented in Fig. 2. In the final analysis, 74 studies were included: 2 observational studies (83 patients), ${ }^{43,44} 65$ case reports or case series (71 patients), ${ }^{8-10,12,16,19,20,23,28-30,45-94,113,118-120} 4$ pharmacokinetic (PK) studies (7 patients), ${ }^{95-98} 1$ descriptive cohort (12 patients), ${ }^{99}$ and 2 in-vitro studies. ${ }^{100,101}$ No randomized controlled trials were identified.

\section{Clinical analysis}

Two observational studies with clinical outcomes related to ECTR were found in the literature review; the first comparing three different types of ECTR (hemodialysis vs charcoal hemoperfusion vs sorbent hemoperfusion) ${ }^{44}$ and the second comparing low-flux hemodialysis to supportive care. ${ }^{43}$ The former study showed a significantly longer duration of artificial ventilation and worse neurological status at 6 and 12 hours in the group receiving hemodialysis; however, the groups were not comparable at baseline, the hemodialysis cohort being more severely poisoned. Thus, any conclusion on the impact of ECTR on the clinical outcome may have been biased by the presence of confounders. In the latter study, groups were also not comparable prior to the intervention (patients in the ECTR group had a higher carbamazepine concentration and a lower Glasgow Coma Score). Allocation was probably subject to confounding-by-indication (i.e., patients who had more significant neurological findings received hemodialysis). Despite 2 fatalities observed in the HD group, the aforementioned biases again preclude any interpretation on the clinical impact of ECTR. The remaining evidence of a clinical effect of ECTR was composed solely of case reports and case series, with absent control groups, multiple potential confounders, heterogeneous treatments, and definite publication bias. The quality of evidence for all recommendation statements would, therefore, be graded as "very low". ${ }^{41}$

An aggregate description of case reports is presented in Table 5. The median carbamazepine ingestion and peak

Statement regarding ECTR for poison " $\mathrm{X}$ "

\section{The workgroup votes on the statement (9-point Likert scale) FOR (7-9) / NEUTRAL (4-6) / AGAINST (1-3)}

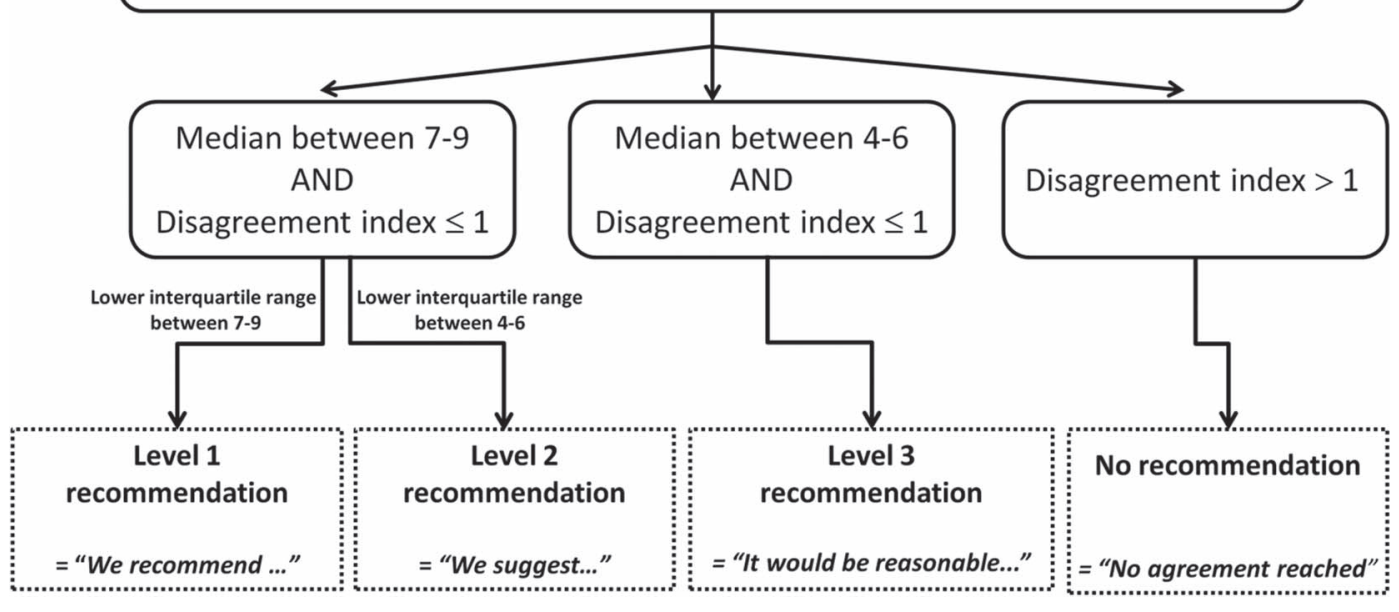

Fig. 1. Strength of recommendation algorithm. 


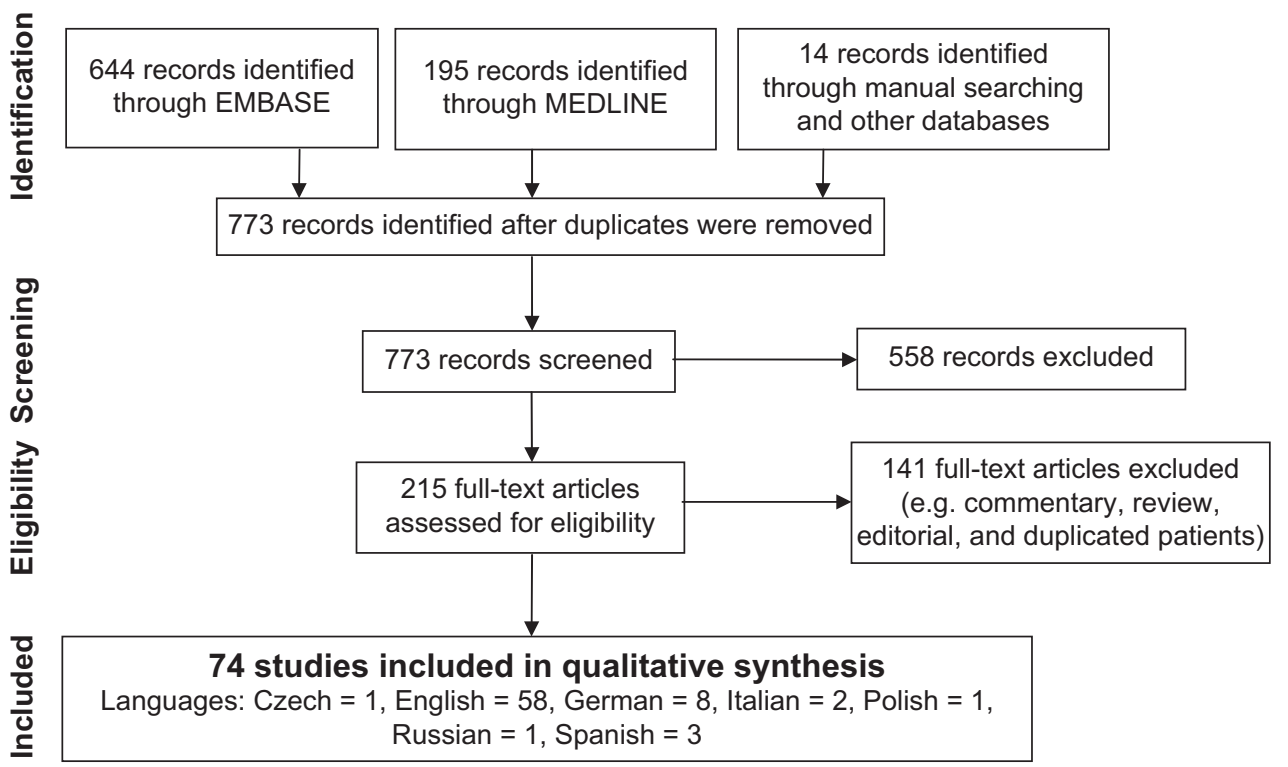

Fig. 2. Flow diagram for the literature search (Last performed Oct 1st 2014).

concentration were 20.9 grams and $46.2 \mathrm{mg} / \mathrm{L}$, respectively. None of the patients were asymptomatic; all had a varying degree of impairment of consciousness, while several experienced either respiratory depression, hypotension, seizures, conduction abnormalities, or a combination of these. Overall, 6 fatalities were described and appeared consequential to carbamazepine exposure instead of

Table 5. Clinical outcomes of the 71 patients described in case reports or case series.

\begin{tabular}{lc}
\hline Patient demographics & \\
Mean age (years) & 27.2 (range 1.3-58) \\
Sex (\% male) & $40.8 \%$ \\
Poisoning exposure & \\
Mean carbamazepine ingestion (grams) & $20.9(0.7-120)$ \\
Mean peak carbamazepine concentration & 46.2 (range 20-130) \\
$\quad$ (mg/L) & \\
Mean delay between ingestion and & 7.8 (range 1-28) \\
$\quad$ admission (hours) & \\
Clinical symptoms and signs & \\
Respiratory depression & $39.4 \%$ \\
Decreased consciousness & $100 \%$ \\
Seizure (1 or more) & $40.8 \%$ \\
Hypotension & $18.3 \%$ \\
Dysrhythmias & $12.7 \%$ \\
Other administered & \\
MDAC & $33.8 \%$ \\
Mechanical ventilation & $56.3 \%$ \\
ECTR & \\
Hemodialysis & $16.9 \%$ \\
Hemoperfusion & $42.2 \%$ \\
Continuous renal replacement therapy & $5.6 \%$ \\
Hemoperfusion-Hemodialysis & $5.6 \%$ \\
Therapeutic plasma exchange & $7.0 \%$ \\
Others & $5.6 \%$ \\
More than 1 ECTR & $16.9 \%$ \\
Outcome & \\
Sequelae & $1.4 \%$ \\
Fatalities & $4.2 \%$ \\
\hline
\end{tabular}

MDAC, Multiple-dose activated charcoal; ECTR, Extracorporeal treatment. *The other fatalities were described in observational cohorts'. the ECTR itself. $19,20,43,90,99$ Although the evidence may be determined as anecdotal, most of the patients who received ECTR (especially hemoperfusion or hemodialysis) appeared to improve rapidly after initiation of the procedure and had an uneventful outcome, including some patients who reportedly ingested doses greater than 500 $\mathrm{mg} / \mathrm{kg},{ }^{29,30,60,62,64,72,85}$ and who had concentrations over $60 \mathrm{mg} / \mathrm{L}(254 \mu \mathrm{mol} / \mathrm{L}) .8,12,16,51,60,66,70,75,79,82,88,120$ Patients receiving less effective treatments, such as continuous renal replacement therapies (CRRT) and peritoneal dialysis, improved less quickly, over days. ${ }^{56,59,85,118}$ Reported complications of ECTRs were almost exclusively associated with hemoperfusion and included hypocalcemia, hypotension, and thrombocytopenia. ${ }^{10,12,23,28,51,62,70,74,76,77,79,91,92}$ Bleeding or a drop in hemoglobin was documented in three cases. ${ }^{50,70,113}$

\section{Toxicokinetic analysis}

Carbamazepine is a small molecule and has a relatively low volume of distribution $\left(\mathrm{V}_{\mathrm{D}}\right)$. Protein binding at therapeutic plasma concentration is significant and decreases slightly, if at all, in overdose. ${ }^{8,9}$ Hemoperfusion would, therefore, be the technique most likely to be efficient. ${ }^{102,103}$ Averaged kinetic parameters for all ECTRs (Table 6), kinetic grading of individual patients (Table 7), as well as comparative studies using both hemoperfusion and hemodialysis, ${ }^{44,64,87}$ suggest that hemoperfusion is the most effective technique for removing carbamazepine; both resin and charcoal hemoperfusion have been used successfully with high clearances in this context, although these are sometimes limited by early saturation of the cartridges, an inconsistent finding. ${ }^{44,53,54,66,72,74,78,79}$

Nevertheless, carbamazepine appears amenable to removal with other ECTRs, such as hemodialysis and hemofiltration that are not commonly assumed to remove protein-bound molecules. ${ }^{104}$ The median clearances for 
Table 6. Median clearance for all ECTRs.

\begin{tabular}{lrl}
\hline Type of ECTRs & N & $\begin{array}{c}\text { Median extracorporeal } \\
\text { clearance }(\mathrm{mL} / \mathrm{min})\end{array}$ \\
\hline Albumin dialysis & 2 & 32.9 (range: $18.8-47)$ \\
Continuous renal replacement therapy & 5 & 18.5 (range: $16-24)$ \\
Hemodialysis & 27 & 59.8 (range: $20-127)$ \\
Hemodialysis-hemoperfusion in series & 2 & 97.8 (range: $86.6-109)$ \\
Hemoperfusion & 28 & 96.9 (range: $23-173)$ \\
Peritoneal dialysis & 1 & 11.7 \\
Exchange transfusion & 1 & 1.5 \\
Therapeutic plasma exchange & 1 & 21.7 \\
\hline
\end{tabular}

* Patients who had more than one ECTR may appear more than once. $\mathrm{N}$, number of patients

hemodialysis were inferior to those for hemoperfusion, but the analyzed data included older articles that did not use the modern filters and high blood flows that are standard today. Most recent reports demonstrate comparable clearances with either hemodialysis and hemoperfusion, exceeding $100 \mathrm{~mL} / \mathrm{min} .{ }^{16,53,64-66,72,76} \mathrm{~A}$ recent retrospective cohort study suggests a greater initial carbamazepine clearance with charcoal hemoperfusion compared with high-flux hemodialysis, although the effect of hemoperfusion became inferior beyond 3 hours which likely represents saturation of the cartridge. ${ }^{44}$ Hemoperfusion was also performed at much greater cost. ${ }^{44,99}$ Current data cannot determine if a combination of hemoperfusion and hemodialysis in series is preferable to either alone. ${ }^{49,61,76,79}$

The determination of carbamazepine dialyzability is supported by several recent publications, ${ }^{59,63-65,75,76,97,119}$ a number of which collected it directly in dialysate or effluent fluid, which is the preferred method to assess dialyzability. 2,105 The literature also included a prospective case series of carbamazepine pharmacokinetics in four end-stage renal disease subjects; although the technical characteristics of the ECTR used in the study are outdated (cuprophane filter and low blood flow), clearance during hemodialysis was twice that calculated endogenously. ${ }^{97}$

Based on the criteria defined in Table $4,{ }^{2}$ most of the cases reviewed for carbamazepine would qualify as either "dialyzable" or "moderately dialyzable." The workgroup preferred a conservative grading and, therefore, agreed with the following statement: carbamazepine is moderately dialyzable (level of evidence $=B$ ).

The data on dialyzability of the metabolite carbamazepine10,11-epoxide are not as abundant as those for carbamazepine. However, its protein binding is less than that of carbamazepine
(50\%), which suggests at least comparable dialyzability. This hypothesis is supported by a few reports. $8,28,53,60$

\section{Comparison of ECTR with MDAC}

MDAC accelerates the elimination of carbamazepine and is currently supported by the latest position statement jointly published by EAPCCT and AACT. ${ }^{27}$ In the rationale, it is suggested that MDAC provides toxicokinetic advantages similar to those of ECTR. ${ }^{116-117}$ The comparison of carbamazepine toxicokinetics in an individual using different techniques is particularly challenging because its elimination in overdose may follow zero-order or first-order elimination kinetics at different concentrations. Nevertheless, in patients where comparative toxicokinetic estimations (from half-life, clearance, or graphical data plots) were possible, ECTR was superior to MDAC in enhancing elimination of carbamazepine. ${ }^{9,23,64,66,69,72,76}$ In one study in particular, carbamazepine's elimination constant $(\mathrm{Ke})$ was $0.009 / \mathrm{h}$ during endogenous metabolism, $0.039 / \mathrm{h}$ during MDAC, and $0.059 / \mathrm{h}$ during hemodialysis. ${ }^{9}$

\section{Recommendations (Table 8)}

1. General statement: ECTR is suggested in severe carbamazepine poisoning (2D)

Rationale: Carbamazepine is a widely used pharmaceutical and has a narrow therapeutic index. Although rarely fatal, poisoning can cause serious clinical effects and result in a prolonged hospital stay. The data suggesting that rapidly reducing carbamazepine concentration by ECTR may lower morbidity are unavailable, but can be extrapolated from the data on MDAC. ${ }^{26}$ Despite the absence of high-quality evidence, the workgroup considered the following arguments:

- The risk of prolonged coma with mechanical ventilation is not benign.

- Complications associated with ECTR are infrequent and usually mild. There is a theoretical concern of provoking withdrawal seizures in a patient with an underlying seizure disorder.

- There are no life-saving antidotes in carbamazepine poisoning. MDAC may enhance its clearance, but the effect is incomplete and often limited by ileus or concerns of pulmonary aspiration in an unprotected airway.

- ECTR can achieve rapid and substantial removal of carbamazepine. ${ }^{69,75}$

Table 7. Kinetic grading for individual patients.

\begin{tabular}{|c|c|c|c|c|c|c|c|c|}
\hline PK/TK grading & TPE & PD & $\mathrm{HP}$ & HD & CRRT & Albumin dialysis & HD-HP (in series) & ET \\
\hline Dialyzable & & & 14 & 8 & & & 1 & \\
\hline Moderately dialyzable & & & 9 & 20 & 3 & 1 & 2 & \\
\hline Slightly dialyzable & 1 & & 3 & 2 & 1 & & & \\
\hline Not dialyzable & & 1 & 1 & 1 & & & & 1 \\
\hline
\end{tabular}

*Patients who had more than 1 ECTR may appear at more than 1 place.

PK, Pharmacokinetics; TK, Toxicokinetics; TPE, Therapeutic plasma exchange; PD, Peritoneal dialysis; HD, Hemodialysis; HP, Hemoperfusion; CRRT, Continuous renal replacement therapy; ET, Exchange transfusion; ECTR: Extracorporeal treatment. 
Table 8. Executive summary of recommendations.

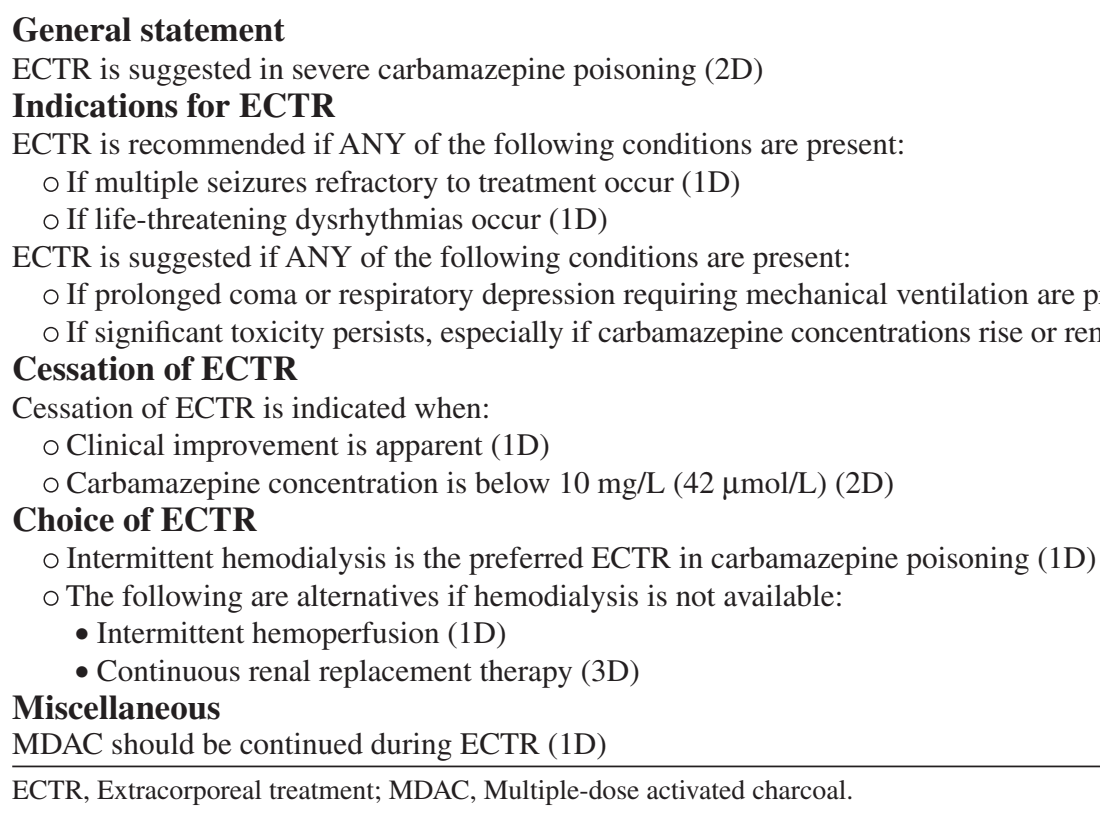

- Although the evidence is anecdotal, patients appear to improve rapidly during ECTR.

For these reasons, the workgroup considered overall that ECTR is worth the risks, costs, and relative uncertainty in patients with severe carbamazepine poisoning, as defined by the conditions below. Most participants (21/28) supported the use of ECTR (voting score, $\geq 7$ ), while the remainder (7/28) had a neutral opinion (voting score, 4-6). While advocating ECTR, the workgroup stated that, in this context, it was unlikely to substantially decrease mortality (as carbamazepine-related fatalities are uncommon) or to avoid irreversible injury (such as it might for blindness in methanol poisoning); instead, ECTR would expectantly be beneficial to reduce short-term morbidity (related to severe hypotension and recurrent seizures) and avoid complications related to prolonged respiratory insufficiency and coma (e.g., ventilator associated pneumonia, pulmonary emboli, and immobilization). Most participants supported the use of ECTR to potentially decrease mechanical ventilation time, intensive care unit (ICU)-related costs, and length of stay in the ICU. ${ }^{46}$ Nevertheless, some participants also considered that active supportive care alone with or without MDAC was sufficient or even preferable to using ECTR in severe carbamazepine poisoning.

2. Indications for ECTR:

ECTR is recommended if ANY of the following conditions are present:

A. If intractable seizures occur (1D)

B. If life-threatening dysrhythmias occur (1D)

ECTR is suggested if ANY of the following conditions are present:
C. If prolonged coma or respiratory depression requiring mechanical ventilation is present or expected (2D)

D. If significant toxicity persists, especially if carbamazepine concentrations rise or remain elevated, despite MDAC and supportive measures (2D)

Rationale: The workgroup proposed that indications for initiation of ECTR in any poisoning should be based on criteria which include exposure (e.g., ingestion, contact, or inhalation), measurement of poison in body fluids, para-clinical tests, and clinical symptoms and signs.

The workgroup agreed that there were too many uncertainties related to the ingested dose to initiate ECTR simply on this information alone. Since serum carbamazepine concentrations are available in the majority of centers, the decision to initiate ECTR should be delayed until confirmation of a toxic exposure becomes possible. Supportive measures, proper gastrointestinal decontamination, and MDAC (as described above) are preferred management for patients presenting after an acute exposure and have no other indication for ECTR. Obviously, if the ingestion history is confirmed and the clinician suspects that major toxicity might ensue (i.e., ingestion $>100 \mathrm{mg} / \mathrm{kg}$ and especially $>20 \mathrm{~g}^{15,106}$ ), early communication with a nephrologist and disposition for possible ECTR are warranted.

Monitoring of serum carbamazepine concentrations can confirm exposure and data can be obtained in a time frame relevant enough to guide clinical decisions. Symptoms appear to be more severe at concentrations greater than $40 \mathrm{mg} / \mathrm{L}(169 \mu \mathrm{mol} / \mathrm{L}),{ }^{14,24}$ although clear correlation with mortality is uncertain. ${ }^{15}$ Nevertheless, the workgroup suggested that isolated elevated carbamazepine concentrations in asymptomatic patients did not warrant ECTR; although several participants stated that some consideration for ECTR should be made at carbamazepine concentrations over $45 \mathrm{mg} / \mathrm{L}(190 \mu \mathrm{mol} / \mathrm{L})$, no formal consensus 
could be obtained at this or any other cutoff. None of the patients identified in our literature review were asymptomatic. Although prophylactic ECTR (i.e., ECTR before the appearance of symptoms) can be considered in poisons where irreversible or life-threatening clinical toxicity can be expected (e.g., paraquat and methanol), the workgroup did not endorse this approach for carbamazepine. The workgroup recognized that children may exhibit more clinical toxicity at an equivalent concentration, perhaps due to a different metabolism and accumulation of the epoxide metabolite, ${ }^{107-109}$ but again the decision to initiate ECTR in this population should be guided on symptoms rather than on an arbitrary serum carbamazepine concentration threshold.

Seizures and dysrhythmias can both follow carbamazepine poisoning and are usually associated with a poorer prognosis. ${ }^{15}$ Obviously, these should be managed with usual supportive therapy as described above. Carbamazepine-induced seizures are possibly induced by accumulation of the epoxide metabolite and are usually singular events when they occur. In the unlikely case that seizures become intractable and unresponsive to conventional therapy, ECTR was strongly recommended by the workgroup. This was also the case for life-threatening dysrhythmias; although the workgroup acknowledged that this was a rare occurrence, ${ }^{24}$ there is some evidence to suggest benefit from rapid carbamazepine removal in this context. ${ }^{9,12,16}$

There was less support for ECTR in carbamazepineinduced coma because this condition was not seen in itself to be as concerning as the above other symptoms. Unlike valproic acid poisoning, where cerebral edema can occur, coma in carbamazepine poisoning is not caused by structural or morphological changes in the CNS. Although not necessarily associated with a poor outcome, ${ }^{15,24}$ coma can be particularly prolonged in massive ingestions and might necessitate protracted mechanical ventilation, in which case there was more agreement to initiate ECTR. Although difficult to estimate clinically, a protracted course can be anticipated in patients with large ingestions, delayed-release preparations, extremely high concentrations, and those who are naïve to carbamazepine (absence of auto-induction in patients on chronic therapy).

Lesser symptoms such as ataxia, ileus, confusion, nystagmus, and mild cardiac conduction defects are associated with a favorable outcome ${ }^{15}$ and were not considered sufficiently severe to justify ECTR.

Increasing carbamazepine concentrations are usually reflective of prolonged absorption which can be managed by MDAC. The inability to administer MDAC was not considered by itself as an indication for ECTR but would reduce its decision threshold for initiation in toxic patients. However, in cases where MDAC is contraindicated, unavailable, could not be adequately performed or unable to reduce carbamazepine concentrations, and with evidence of clinical toxicity, ECTR was recommended by the workgroup. This was also the case in patients who fail supportive therapy.
3. Cessation of ECTR: ECTR is indicated until sustained clinical improvement is apparent (1D) or carbamazepine serum concentration is below $10 \mathrm{mg} / \mathrm{L}$ $(42 \mu \mathrm{mol} / \mathrm{L})(2 \mathrm{D})$

Rationale: One of the intents of beginning ECTR in patients with carbamazepine poisoning is to reduce complications associated with prolonged coma and hypoventilation. It is, therefore, reasonable to pursue ECTR until clinical improvement becomes apparent. This improvement should be sustained for a period of time long enough to account for any ongoing absorption. Although a high carbamazepine concentration is not by itself an indication of initiating ECTR, the workgroup agreed that below $10 \mathrm{mg} / \mathrm{L}(42 \mu \mathrm{mol} / \mathrm{L})$, most toxic symptoms would be expected to resolve.

Clinicians should continue to monitor carbamazepine concentrations regularly after ECTR, as concentrations may rebound. This was present in one-third of patients reviewed from our cohort and is particularly concerning if caused by ongoing absorption, ${ }^{76}$ as improvement of ileus will in turn augment carbamazepine absorption. If concentrations rebound to threatening levels or if there is recurrence of toxic symptoms, another ECTR session may be indicated. For this reason, the central venous catheter should only be removed once the clinician is assured that ECTR is no longer needed.

4. Choice of ECTR: Intermittent hemodialysis is the preferred modality for ECTR in carbamazepine poisoning (1D). Intermittent hemoperfusion (1D) and continuous renal replacement modalities (3D) are alternatives if intermittent hemodialysis is not available.

Rationale: The workgroup agreed that hemodialysis is the preferred modality of ECTR in carbamazepine poisoning. Although historical preference was given to intermittent hemoperfusion, because of its theoretical advantage of clearing protein-bound poisons such as carbamazepine, there are several arguments that now favor the use of intermittent hemodialysis:

- Recent data suggest that hemodialysis is almost as effective as hemoperfusion ${ }^{9,64,87}$ due to improved clearances provided by newer high-flux and high-efficiency synthetic membranes compared with those provided by older less efficient cuprophane dialyzers. Present-day catheters can also achieve blood flows during hemodialysis up to $400 \mathrm{~mL} / \mathrm{min}$, while blood flow for several hemoperfusion cartridges remains limited to 300-350 $\mathrm{mL} / \mathrm{min}^{68}$ because of the risk of hemolysis. ${ }^{110}$

- Intermittent hemodialysis is the favored treatment for maintenance dialysis in patients with end-stage kidney disease (ESRD) and acute kidney injury (AKI) worldwide; therefore, this is the most available modality. Meanwhile, hemoperfusion cartridges are of limited availability in many parts of the world, as is the accessibility to online hemofiltration. Therefore, the travel distance to a hemodialysis center for a poisoned patient would likely be minimized. 
- More physicians and nurses are experienced with hemodialysis, with lesser risks of delay and uncertainty.

- The complication rate with hemodialysis appears favorable in comparison to hemoperfusion. ${ }^{11}$ At least one third of the patients evaluated in the present cohort experienced thrombocytopenia during hemoperfusion.

- The cost of hemodialysis favors it over hemoperfusion. This is largely explained by the cost of monitoring and treating complications as well as the lower cost of dialysis filters versus charcoal cartridges, which need to be replaced regularly because of saturation of its adsorptive capacity. ${ }^{44}$

Nevertheless, in the rare case where hemoperfusion, but not hemodialysis is available, it would be an acceptable alternative, if cartridges are available and if physicians and nursing personnel are comfortable with this technique. Similarly, it is anticipated that carbamazepine would be removed by intermittent convection-based techniques (online HF) ${ }^{62}$

Continuous techniques offer markedly lower clearances and removal rates compared with intermittent techniques ${ }^{60,76,85,113,119}$ and, as such, are considered to be inferior modalities by EXTRIP and only advocated if hemodialysis is not available (due to technical or staffing reasons in critical care settings). Continuous techniques are usually better tolerated hemodynamically than intermittent techniques, although this is mostly true in cases where net fluid removal is necessary, which would be an unusual requirement in carbamazepine poisoning. Peritoneal dialysis, ${ }^{59}$ exchange transfusion, ${ }^{95}$ and plasma exchange ${ }^{63}$ do not offer comparable results to hemodialysis or hemoperfusion, as expected, ${ }^{112}$ and are not currently recommended. Limited data for albumin-enhanced techniques are available, ${ }^{46,73,113,119}$ but these procedures are extremely costly and have not shown superiority to either hemoperfusion or hemodialysis; in one study, the addition of $20 \%$ albumin in the dialysate increased clearance by $24 \% .^{119}$

Whatever the technique is used, operating ECTR characteristics should be optimized to maximize removal, that is, high blood and dialysate flow rates, ${ }^{104,114,119}$ high surface area filters, and longer duration of ECTR. ${ }^{104}$

5. Miscellaneous: MDAC therapy should be continued during ECTR (1D)

Rationale: MDAC may enhance elimination of carbamazepine, may reduce toxicity in carbamazepine-poisoned patients, ${ }^{26}$ and is currently recommended for this indication by various toxicology societies. ${ }^{27}$ The workgroup supported MDAC during ECTR in patients who did not present contraindications to its use. Its effect on elimination would likely be additive to ECTR and should be used whenever the airway is protected, either by the patient's own reflexes or an endotracheal tube..$^{9,64,72}$

\section{Conclusion}

Here, the EXTRIP workgroup presents its recommendations for ECTRs in carbamazepine poisoning. The evidence suggests that elimination enhancement with intermittent hemodialysis or hemoperfusion is superior to MDAC. In the large majority of patients with toxic carbamazepine exposures, supportive management appears sufficient. However, in severe cases, the group supported the use of ECTR on the basis that advantages superseded costs and risks associated with the procedures, despite an absence of robust clinical studies.

\section{Acknowledgements}

We would like to acknowledge the tremendous work of our dedicated translators: Marcela Covica, Alexandra Angulo, Ania Gresziak, Samantha Challinor, Martine Blanchet, Gunel Alpman, Joshua Pepper, Lee Anderson, Andreas Betz, Tetsuya Yamada, Nathalie Eeckhout, Matthew Fisher, Ruth Morton, Denise Gemmellaro, Monique Cormier, Nadia Bracq, Olga Bogatova, Sana Ahmed, Christiane Frasca, Katalin Fenyvesi, Timothy Durgin, Helen Johnson, Martha Oswald, Ewa Brodziuk, David Young, Akiko Burns, Anna Lautzenheiser, Banumathy Sridharan, Charlotte Robert, Liliana Ionescu, Lucile Mckay, Vilma Etchart, Valentina Bartoli, Nathan Weatherdon, Marcia Neff, Margit Tischler, Sarah Michel, Simona Vairo, Mairi Arbuckle, Luc Ranger, Nerissa Lowe, Angelina White, Salih Topal, John Hartmann, Karine Mardini, Mahala Bartle Mathiassen, Anant Vipat, Gregory Shapiro, Hannele Marttila, and Kapka Lazorova.

We also acknowledge the important contribution from our librarians and secretarial aids: Marc Lamarre, David Soteros, Salih Topal, Henry Gaston, and Brenda Gallant.

\section{Financial disclosure}

Funding for EXTRIP was obtained from industry in the form of unrestricted educational grants. These funds were used solely for expenses related to literature retrieval, translation of publications, and for reimbursement of conference calls and travel expenses for attendance at EXTRIP meetings. The authors declare that they have no competing interests. A list of EXTRIP sponsors can be found on www.extripworkgroup.org. There was no industry input into meeting organization, scientific content, development, or publication of the recommendations. Furthermore, presence of industry at meetings was not allowed, nor was industry awareness or comment on the recommendations sought or accepted.

\section{Declaration of interest}

No capitalization of disclosure and non-financial conflict of interests: The authors declare that they have no conflict of interest financial or otherwise related to this work. Complete financial disclosure for each EXTRIP member can be found at www.extrip-workgroup.org.

\section{References}

1. Ghannoum M, Nolin TD, Lavergne V, Hoffman RS. Blood purification in toxicology: nephrology's ugly duckling. Adv Chronic Kidney Dis 2011; 18:160-166.

2. Lavergne V, Nolin TD, Hoffman RS, Robert D, Gosselin S, Goldfarb DS, et al. The EXTRIP (Extracorporeal Treatments In 
Poisoning) workgroup: guideline methodology. Clin Toxicol 2012; 50:403-413.

3. Ghannoum M, Lavergne V, Nolin TD, Hoffman RS. The utility of extracorporeal treatment for acute thallium poisoning: the first recommendation from the Extracorporeal Treatment in Poisoning Workgroup. Clin Toxicol 2012; 50:574-720.

4. Yates C, Galvao T, Sowinski KM, Mardini K, Botnaru T, Gosselin S, et al. Extracorporeal treatment for tricyclic antidepressant poisoning: recommendations from the EXTRIP workgroup. Semin Dial. 2014; 27:381-389.

5. Mactier R, Laliberte M, Mardini J, Ghannoum M, Lavergne V, Gosselin S, et al. Extracorporeal treatment for barbiturate poisoning: recommendations from the EXTRIP workgroup. Am J Kidney Dis 2014; 64:347-358.

6. Gosselin S, Juurlink DN, Kielstein JT, Ghannoum M, Lavergne V, Nolin TD, Hoffman RS. Extracorporeal treatment for acetaminophen poisoning: Recommendations from the EXTRIP workgroup. Clin Toxicol (Phila) 2014; 52:856-867.

7. Spiller HA. Management of carbamazepine overdose. Pediatr Emerg Care 2001; 17:452-456.

8. Vree TB, Janssen TJ, Hekster YA, Termond EF, van de Dries AC, Wijnands WJ. Clinical pharmacokinetics of carbamazepine and its epoxy and hydroxy metabolites in humans after an overdose. Ther Drug Monit 1986;8:297-304.

9. Sikma MA, van den Broek MP, Meulenbelt J. Increased unbound drug fraction in acute carbamazepine intoxication: suitability and effectiveness of high-flux haemodialysis. Intensive Care Med 2012; 38:916-917.

10. Lurie Y, Bentur Y, Levy Y, Baum E, Krivoy N. Limited efficacy of gastrointestinal decontamination in severe slow-release carbamazepine overdose. Ann Pharmacother 2007; 41:1539-1543.

11. Package insert. Tegretol (carbamazepine) USP chewable tablets of $100 \mathrm{mg}$, tablets $200 \mathrm{mg}$, suspension $100 \mathrm{mg} / 5 \mathrm{ml}$, Tegretol-XR, carbamazepine extended-release tablets $100 \mathrm{mg}, 200 \mathrm{mg}, 400 \mathrm{mg}$. . East Hanover, NJ: Novartis Pharmaceutical Corp; 2006.

12. Cameron RJ, Hungerford P, Dawson AH. Efficacy of charcoal hemoperfusion in massive carbamazepine poisoning. J Toxicol Clin Toxicol 2002; 40:507-512.

13. Guntelberg E. Carbamazepine tegretol poisoning. A review and case report. Ugeskr Laeger. 1967; 129:161-163.

14. Hojer J, Malmlund HO, Berg A. Clinical features in 28 consecutive cases of laboratory confirmed massive poisoning with carbamazepine alone. J Toxicol Clin Toxicol 1993; 31:449-458.

15. Schmidt S, Schmitz-Buhl M. Signs and symptoms of carbamazepine overdose. J Neurol 1995; 242:169-173.

16. Leslie PJ, Heyworth R, Prescott LF. Cardiac complications of carbamazepine intoxication: treatment by haemoperfusion. Br Med J (Clin Res Ed) 1983; 286:1018.

17. Megarbane B, Leprince P, Deye N, Guerrier G, Resiere D, Bloch V, Baud FJ. Extracorporeal life support in a case of acute carbamazepine poisoning with life-threatening refractory myocardial failure. Intensive Care Med. 2006; 32:1409-1413.

18. Schwartau M, Wahl G, Bucking J. Intramyocardial block in carbamazepine poisoning. Dtsch Med Wochenschr 1983; 108(48): 1841-1843.

19. Martin-Echevarria E, De Arriba G, Pereira-Julia A, Albaya A. Acute carbamazepine intoxication treated with hemoperfusion. Rev Clin Esp 2006; 206:300.

20. Hruby K, Lenz K, Druml W, Kleinberger G. Experiences with acute carbamazepine poisoning. Nervenarzt 1982; 53:414-418.

21. de Zeeuw RA, Westenberg HG, van der Kleijn E, Gimbrere JS. An unusual case of carbamazepine poisoning with a near-fatal relapse after two days. Clin Toxicol 1979; 14:263-269.

22. Sethna M, Solomon G, Cedarbaum J, Kutt H. Successful treatment of massive carbamazepine overdose. Epilepsia 1989; 30:71-73.

23. Graudins A, Peden G, Dowsett RP. Massive overdose with controlled-release carbamazepine resulting in delayed peak serum concentrations and life-threatening toxicity. Emerg Med (Fremantle) 2002; 14:89-94.
24. Spiller HA, Krenzelok EP, Cookson E. Carbamazepine overdose: a prospective study of serum levels and toxicity. J Toxicol Clin Toxicol 1990; 28:445-458.

25. Chyka PA, Seger D, Krenzelok EP, Vale JA, American Academy of Clinical Toxicology; European Association of Poisons Centres and Clinical Toxicologists. Position paper: single-dose activated charcoal. Clin Toxicol (Phila) 2005; 43:61-87.

26. Brahmi N, Kouraichi N, Thabet H, Amamou M. Influence of activated charcoal on the pharmacokinetics and the clinical features of carbamazepine poisoning. Am J Emerg Med 2006; 24:440-443.

27. Vale J, Krenzelok, EP, Barceloux VD. Position statement and practice guidelines on the use of multi-dose activated charcoal in the treatment of acute poisoning. American Academy of Clinical Toxicology; European Association of Poisons Centres and Clinical Toxicologists. J Toxicol Clin Toxicol 1999;37:731-751.

28. Deshpande G, Meert KL, Valentini RP. Repeat charcoal hemoperfusion treatments in life threatening carbamazepine overdose. Pediatr Nephrol 1999; 13:775-777.

29. Soderstrom J, Murray L, Little M, Daly FF. Toxicology case of the month: carbamazepine overdose. Emerg Med J 2006; 23 : 869-871.

30. Ozsarac M, Sever M, Gokova S, Ersel M, Sezis M. Massive carbamazepine overdose: any role of hemodialysis? Case report. Turkiye Klinikleri J Med Sci 2011; 31:702-705.

31. Sud A, Chidley K. A role for intravenous lipid emulsion in cardiac arrest secondary to life-threatening carbamazepine overdose. Anaesthesia 2013; 68:989.

32. Hurley WT, Hanlon P. Lipid Emulsion as an Antidote at the Washington Poison Center; Use in Carbamazepine, Flecanide, Hydroxychloroquine, Bupivacaine, and Bupropion. Clin Toxicol 2009; 47:729.

33. Carbamazepine. May 24, 2013. Managements Greenwood Village (CO): Thomson Reuters (Healthcare) IncPOISINDEX ${ }^{\circledR}$. Available from: http://www.thomsonhc.com.

34. Greene S, O'Connor A. Carbamazepine poisoning. 2013 October 28th 2013 [cited May 15th 2014]. In: UpToDate [Internet]. Waltham, MA, [cited May 15th 2014].

35. Doyon S. Anticonvulsants. In: Nelson LS, Lewin NA, Howland MA, Hoffman RS, Goldfrank LR, Neal F, eds. Goldfrank's Toxicologic Emergencies. New York, NY: McGraw-Hill; 2011:698-710.

36. Fountain J. Phenytoin. 2014 [cited August 15th 2014]. In: Toxinz [Internet]. New Zealand, [cited August 15th 2014]. Available from: http://www.toxinz.com/Spec/1899192\#secrefID0EUNAG.

37. Kapoor N. Carbamazepine toxicity treatment \& management. 2012 March 292012 [cited 24 May 2014]. EMedicine, [cited 24 May 2014]. Available from:http://emedicine.medscape.com/ article/813654-treatment\#a1129

38. Carbamazepine. 2013 [cited March 23 2014]. In: Wiki Tox [Internet]. [cited March 23 2014]. Available from: http://curriculum.toxicology. wikispaces.net/3.4.2.3 + Carbamazepine.

39. Furlanut M, Franceschi L, Poz D, Silvestri L, Pecorari M. Acute oxcarbazepine, benazepril, and hydrochlorothiazide overdose with alcohol. Ther Drug Monit 2006; 28:267-268.

40. Appraisal of guidelines for research \& evaluation. AGREE instrument. London: The AGREE Collaboration; 2001.

41. Atkins D, Best D, Briss PA, Eccles M, Falck-Ytter Y, Flottorp S, et al. Grading quality of evidence and strength of recommendations. BMJ. 2004; 328:1490.

42. Fitch K, Bernstein SJ, Aguilar MD, Burnand B, LaCalle JR, Lazaro P, et al. The RAND/UCLA Appropriateness Method User's Manual. Santa Monica, CA2011. Available from: http://www. rand.org/. Accessed on April 10th 2014.

43. Ozhasenekler A, Gokhan S, Guloglu C, Orak M, Ustundag M. Benefit of hemodialysis in carbamazepine intoxications with neurological complications. Eur Rev Med Pharmacol Sci 2012; $16: 43-47$.

44. Maslov OG, Brusin KM, Kochmashev VF, Sentsov VG. Comparative evaluation of methods of extracorporeal detoxification in acute carbamazepine poisoning. Klinicheskaia Toksikologiia (Russia) 2011;12. 
45. Ash SR, Levy H, Akmal M, Mankus RA, Sutton JM, Emery DR, et al. Treatment of severe tricyclic antidepressant overdose with extracorporeal sorbent detoxification. Adv Ren Replace Ther 2002; 9:31-41.

46. Askenazi DJ, Goldstein SL, Chang IF, Elenberg E, Feig DI. Management of a severe carbamazepine overdose using albuminenhanced continuous venovenous hemodialysis. Pediatrics 2004; 113:406-409.

47. Azak A, Kocak G, Huddam B, Duranay M. Is conventional hemodialysis enough to manage carbamazepine intoxication? Blood Purif 2012; 33:225-226.

48. Bek K, Kocak S, Ozkaya O, Yilmaz Y, Aydin OF, Tasdoven CS. Carbamazepine poisoning managed with haemodialysis and haemoperfusion in three adolescents. Nephrology (Carlton) 2007; 12:33-35.

49. Bock E, Keller F, Heitz J, Heinemeyer G. Treatment of carbamazepine poisoning by combined hemodialysis/hemoperfusion. Int $\mathrm{J}$ Clin Pharmacol Ther Toxicol 1989; 27:490-492.

50. Brodersen HP, Glitz HH, Minderjahn KP, Larbig D. Therapeutic aspects of intoxications with carbamazepine, lithium, and doxepin. Intensivmed Notfallmed 1986; 23:273-276.

51. Chan KM, Aguanno JJ, Jansen R, Dietzler DN. Charcoal hemoperfusion for treatment of carbamazepine poisoning. Clin Chem 1981; 27:1300-1302.

52. Chetty M, Sarkar P, Aggarwal A, Sakhuja V. Carbamazepine poisoning: treatment with haemodialysis. Nephrol Dial Transplant 2003; $18: 220-221$.

53. de Groot G, van Heijst AN, Maes RA. Charcoal hemoperfusion in the treatment of two cases of acute carbamazepine poisoning. J Toxicol Clin Toxicol 1984; 22:349-362.

54. Derzsiova K, Mydlik M, Petrikova V. Hemoperfusion study with carbamazepine in vitro. Int J Artif Organs 1999; 22:730-733.

55. Duzova A, Baskin E, Usta Y, Ozen S. Carbamazepine poisoning: treatment with plasma exchange. Hum Exp Toxicol 2001; 20: 175-177.

56. Gambi D, Oggioni R, Mangani V, Librenti M, Manescalchi F, Tulli G. Acute carbamazepine poisoning treated with plasmapheresis. Description of a clinical case. Minerva Anestesiol 1993; 59: 547-552.

57. Gary NE, Byra WM, Eisinger RP. Carbamazepine poisoning: treatment by hemoperfusion. Nephron 1981; 27:202-203.

58. Goktas U, Kati I, Yuce HH. Management of a severe carbamazepine overdose with continuous venovenous hemodiafiltration. Am J Emerg Med 2010; 28:260 e1-2.

59. Gruska H, Beyer KH, Kubicki S, Schneider H. Course, toxicology and therapy of a case of carbamazepin poisoning. Arch Toxikol 1971; 27:193-203.

60. Harder JL, Heung M, Vilay AM, Mueller BA, Segal JH. Carbamazepine and the active epoxide metabolite are effectively cleared by hemodialysis followed by continuous venovenous hemodialysis in an acute overdose. Hemodial Int 2011; 15: 412-415.

61. Hartleib H, Nitzsche W, Stople HJ, Rohmann E, Druckler E, Wigger M. Hemoperfusion for carbamazepine intoxication. Z Klin Med 1985; 40:441-443.

62. Isik Y, Soyoral L, Karadas S, Emre H, Cegin MB, Goktas U. Effectivity of one session charcoal hemoperfusion treatment in severe carbamazepine poisoning. Iran Red Crescent Med J 2013; 15:749-751.

63. Kale PB, Thomson PA, Provenzano R, Higgins MJ. Evaluation of plasmapheresis in the treatment of an acute overdose of carbamazepine. Ann Pharmacother 1993; 27:866-870.

64. Kielstein JT, Schwarz A, Arnavaz A, Sehlberg O, Emrich HM, Fliser D. High-flux hemodialysis-an effective alternative to hemoperfusion in the treatment of carbamazepine intoxication. Clin Nephrol 2002; 57:484-486.

65. Koh KH, Tan HH. High-flux haemodialysis treatment as treatment for carbamazepine intoxication. Med J Malaysia 2006; 61:109-111.
66. Kolacinski Z, Winnicka R, Lopacinski B, Kolacinska M. Carbamazepine "CR"-clinical picture of intoxication: the kinetics of extracorporeal elimination. Przegl Lek 2005; 62:482-485.

67. Kuhlmann U, Becker R, Ebel H, Gressner A, Lange H. Extracorporeal elimination of carbamazepine by haemoperfusion. Biomater Artif Cells Immobilization Biotechnol 1992; 20: 1171-1176.

68. Li TG, Yan Y, Wang NN, Zhao M. Acute carbamazepine poisoning treated with resin hemoperfusion successfully. Am J Emerg Med 2011; 29:518-522.

69. Low CL, Haqqie SS, Desai R, Bailie GR. Treatment of acute carbamazepine poisoning by hemoperfusion. Am J Emerg Med 1996;14:540-541.

70. Milonovich LM, Headrick CL, Seikaly M, Morriss FC. Charcoal hemoperfusion via a continuous venovenous hemofiltration circuit to treat carbamazepine overdose. Crit Care Nurse 2001; 21:25-28.

71. Montoya-Cabrera MA, Sanchez-Suarez BA, Hernandez-Zamora A, Murguia-Chavez LM. Treatment of acute carbamazepine intoxication according to its pharmacological properties. Preliminary report. Arch Invest Med (Mex) 1980; 11:417-424.

72. Muller CH, Lankisch PG. Resin hemoperfusion for carbamazepine intoxication. Intensivmed Notfallmed 1989; 26:145-148.

73. Narayan R, Rizzo M, Cole M. Successful treatment of severe carbamazepine toxicity with 5\% albumin-enhanced continuous venovenous hemodialysis. J Artif Organs 2014; 17:206-209.

74. Nilsson C, Sterner G, Idvall J. Charcoal hemoperfusion for treatment of serious carbamazepine poisoning. Acta Med Scand 1984; 216:137-140.

75. O’Malley G, Zebley T, Wilcox B, Raja R, Firpo J. A massive carbamazepine overdose treated with high-efficiency hemodialysis. Clin Toxicol (Phila) 2006; 44:684-685.

76. Payette A, Ghannoum M, Madore F, Albert M, Troyanov S, Bouchard J. Carbamazepine poisoning treated by multiple extracorporeal treatments. Clin Nephrol 2014

77. Peces R, Azorin S, Peces C, Selgas R. Extended hemoperfusion in the treatment of acute carbamazepine intoxication. Nefrologia 2010; 30:127-130.

78. Piantanida S, Bolis C, Cattaneo A, Cosci P, Rivolta G. Charcoal hemoperfusion as treatment for carbamazepine acute intoxication. Acta Anaesthesiol Ital 1995; 46:191-194.

79. Pilapil M, Petersen J. Efficacy of hemodialysis and charcoal hemoperfusion in carbamazepine overdose. Clin Toxicol (Phila) 2008; 46:342-343.

80. Prchlik R, Marsik S. Importance of hemoperfusion during poisoning of carbamazepine - a case report. Anesteziologie a Neodkladna Pece 2001; 12:143-144.

81. Ram Prabahar M, Raja Karthik K, Singh M, Singh RB, Singh S, Dhamodharan J. Successful treatment of carbamazepine poisoning with hemodialysis: a case report and review of the literature. Hemodial Int 2011; 15:407-411.

82. Saygan-Karamursel B, Guven S, Onderoglu L, Deren O, Durukan T. Mega-dose carbamazepine complicating third trimester of pregnancy. J Perinat Med 2005; 33:72-75.

83. Schlafke D, Kloock R. Carbamazepine poisoning. Anaesthesiol Reanim 1991; 16:220-224.

84. Schuerer DJ, Brophy PD, Maxvold NJ, Kudelka T, Bunchman TE. High-efficiency dialysis for carbamazepine overdose. J Toxicol Clin Toxicol 2000; 38:321-323.

85. Shah S, Tomlin M, Sparkes D. Lack of effect of high-volume continuous veno-venous haemofiltration with dialysis in massive carbamazepine overdose. BMJ Case Rep 2012;2012.

86. Springer W, Greiner C, Wehran HJ. Successful hemodialysis/hemo perfusion in a small child intoxicated by a mixture of phenytoin and carbamezepine. Z Klin Med 1987; 42:1401-1402.

87. Tapolyai M, Campbell M, Dailey K, Udvari-Nagy S. Hemodialysis is as effective as hemoperfusion for drug removal in carbamazepine poisoning. Nephron 2002; 90:213-215.

88. Tibballs J. Acute toxic reaction to carbamazepine: clinical effects and serum concentrations. J Pediatr 1992; 121:295-299. 
89. Unei H, Ikeda H, Murakami T, Tanigawa K, Kihira K. Detoxication treatment for carbamazepine and lithium overdose. Yakugaku Zasshi 2008; 128:165-170.

90. Varela P, Ríos P, Gelabert B, García C, Bagnulo H. Acute intoxication with carbamazepine: treatment with hemoperfusion and hemofiltration. Arch Med Interna 2001; 23:107-110.

91. Vree T, Geerts Y, van Dalen R. Disposition kinetics of a severe overdose of carbamazepine. J Appl Ther 1997; 1:265-270.

92. Vree T, Von Dalen R, Geerts Y, Van Ewijk E. Clinical pharmacokinetics of a massive overdose of carbamazepine and acute renal failure. Clin Drug Invest 1997; 14:66-75.

93. Yaylaci S, Demir MV, Acar B, Sipahi S, Tamer A. Successful treatment of excessive dose of carbamazepine. Indian J Pharmacol 2012; 44:417-418.

94. Yildiz TS, Toprak DG, Arisoy ES, Solak M, Toker K. Continuous venovenous hemodiafiltration to treat controlled-release carbamazepine overdose in a pediatric patient. Paediatr Anaesth 2006; 16:1176-1178.

95. Bradley JM, Sagraves R. Effect of exchange-reduction transfusion on carbamazepine. Clin Pharm 1984; 3:585.

96. Kandrotas RJ, Oles KS, Gal P, Love JM. Carbamazepine clearance in hemodialysis and hemoperfusion. DICP 1989; 23:137-140.

97. Lee CS, Wang LH, Marbury TC, Bruni J, Perchalski RJ. Hemodialysis clearance and total body elimination of carbamazepine during chronic hemodialysis. Clin Toxicol 1980; 17:429-438.

98. Siddiqi ZA, Holt A, Ahmed SN. Effect of plasma exchange on carbamazepine levels in a patient with myasthenia gravis and epilepsy. Epilepsia 2005; 46:1841-1842.

99. Sentsov VG, Brusin KM, Meledin VY, Novikova OV, Urazaev TH. Comparison of charcoal hemoperfusion and hemodialysis in treatment of severe carbamazepine intoxications. Clin Toxicol (Phila) 2007; 45:346.

100. Fischer S, Mueller D, Rentsch K, Ceschi A, Rauber-Luethy C. In vitro testing of plasma protein binding of carbamazepine in relation to serum concentration. Clin Toxicol 2010; 48:652.

101. Becker R, Kuhlmann U, Ebel H, Gressner A, Lange H. Carbamazepine intoxication: about the efficiency of hemoperfusion. Intensivmed Notfallmed 1991; 28:78-81.

102. Ghannoum M, Bouchard J, Nolin TD, Ouellet G, Roberts DM. Hemoperfusion for the treatment of poisoning: technology, determinants of poison clearance, and application in clinical practice. Semin Dial 2014; 27:350-361.

103. Ghannoum M, Roberts DM, Hoffman RS, Ouellet G, Roy L, Decker BS, Bouchard J. A stepwise approach for the management of poisoning with extracorporeal treatments. Semin Dial 2014; 27 : 362-370.

104. Bouchard J, Roberts DM, Roy L, Ouellet G, Decker BS, Mueller BA, et al. Principles and operational parameters to optimize poison removal with extracorporeal treatments. Semin Dial 2014; 27:371-380.

\section{Notice of Correction}

Since this article was posted online on 30 Oct 2014 there have been revisions to the figures, text and tables.
105. Lavergne V, Ouellet G, Bouchard J, Galvao T, Kielstein JT, Roberts DM, et al. Guidelines for Reporting Case Studies on Extracorporeal Treatments in Poisonings: Methodology. Semin Dial. 2014; 27:407-414.

106. De Rubeis DA, Young GB. Continuous EEG monitoring in a patient with massive carbamazepine overdose. J Clin Neurophysiol 2001; 18:166-168.

107. Stremski ES, Brady WB, Prasad K, Hennes HA. Pediatric carbamazepine intoxication. Ann Emerg Med 1995; 25:624-630.

108. Bridge TA, Norton RL, Robertson WO. Pediatric carbamazepine overdoses. Pediatr Emerg Care 1994; 10:260-263.

109. Pynnonen S, Sillanpaa M, Frey H, Iisalo E. Carbamazepine and its 10,11-epoxide in children and adults with epilepsy. Eur J Clin Pharmacol 1977; 11:129-133.

110. Rahman MH, Haqqie SS, McGoldrick MD. Acute hemolysis with acute renal failure in a patient with valproic acid poisoning treated with charcoal hemoperfusion. Hemodial Int 2006; 10:256-259.

111. Shannon MW. Comparative efficacy of hemodialysis and hemoperfusion in severe theophylline intoxication. Acad Emerg Med 1997; 4:674-678.

112. Ouellet G, Bouchard J, Ghannoum M, Decker BS. Available extracorporeal treatments for poisoning: overview and limitations. Semin Dial 2014; 27:342-349.

113. Chung YK, Chang KY, Park HS, Kim MH, Lee KM, Lim TS, Kim HW. Severe carbamazepine intoxication unresponsive to albumin-enhanced continuous venovenous hemodiafiltration with low dialysate flow. Hemodial Int 2014; 18:551-555.

114. Churchwell MD, Pasko DA, Smoyer WE, Mueller BA. Enhanced clearance of highly protein-bound drugs by albumin-supplemented dialysate during modeled continuous hemodialysis. Nephrol Dial Transplant 2009; 24:231-238.

115. Mowry JB, et al. 2012 annual report of the American association of poison control centers' national poison data system (NPDS): 30th annual report. Clin Toxicol (Phila) 2013; 51:949-1229.

116. Neuvonen PJ and Elonen E . Effect of activated charcoal on absorption and elimination of phenobarbitone, carbamazepine and phenylbutazone in man. Eur J Clin Pharmacol 1980; 17:51-57.

117. Montoya-Cabrera JB, et al. Carbamazepine poisoning in adolescent suicide attempters. Effectiveness of multiple-dose activated charcoal in enhancing carbamazepine elimination. Arch Med Res 1996; 27:485-489.

118. Kozanoglu I, Kahveci S, Asma S, et al. Plasma-exchange treatment for severe carbamazepine intoxication: a case study. J Clin Apher. 2014;29(3):178-180.

119. Choi JS, Kim CS, Bae EH, et al. Enhanced clearance of carbamazepine using albumin-containing dialysate during CVVHDF. Intensive Care Med. 2013;39(1):159-160.

120. Levine M, Bosak A, Yee B, Tran A. Carbamazepine induced seizures and ventricular dysrhythmias. Clin Toxicol (Phila). 2013;51(7): 575-724. 